\title{
Souffrances sociales. Philosophie, psychologie et politique Emmanuel Renault
}

DOI: 10.3395/reciis.v2i2.220pt

\section{Michel Thiollent}

Coppe, Universidade Federal do Rio de Janeiro, Rio de Janeiro, Brasil

thiollent@pep.ufrj.br

O livro de Emmanuel Renault, professor de filosofia da École Normale Supérieure de Lyon, apresenta uma interessante e abrangente síntese de estudos recentes sobre o conceito de sofrimento social, com base em filosofia, psicologia e ciência política.

Sofrimento social (no singular ou no plural) é hoje um termo muito utilizado em ciências sociais, que abrange diferentes aspectos relacionados com a perda de qualidade de vida, podendo ser vivenciado tanto no plano individual (psicopatologia decorrente de condições de trabalho desumano, do desemprego ou do trabalho precário, por exemplo) quanto no plano coletivo (malestar na sociedade, degradação do quadro de vida de comunidades, situação de dominação, exclusão social, violência, assédio moral etc.). Esse termo é também evocado em debates políticos sobre os rumos da sociedade, ou das políticas públicas, para apontar os problemas relacionados com as condições de existência ou com a exclusão social de certas categorias da população. Em tais debates, com freqüência, o sofrimento social é associado aos recentes efeitos do neoliberalismo, em particular o da precarização do emprego e o das limitações impostas à proteção social dos assalariados e dos desempregados.

Embora o sofrimento social tenha existido em diversas sociedades e épocas (sofrimentos vinculados, por exemplo, à situação dos trabalhadores no início da industrialização na Europa do século XIX, à escravidão em países colonizados, ao trabalho forçado ou a outras práticas autoritárias), o uso intensivo do correspondente conceito nas ciências sociais é bastante recente. No contexto francês, um autor que contribui muito para sua divulgação é Christophe Dejours, psicólogo do trabalho

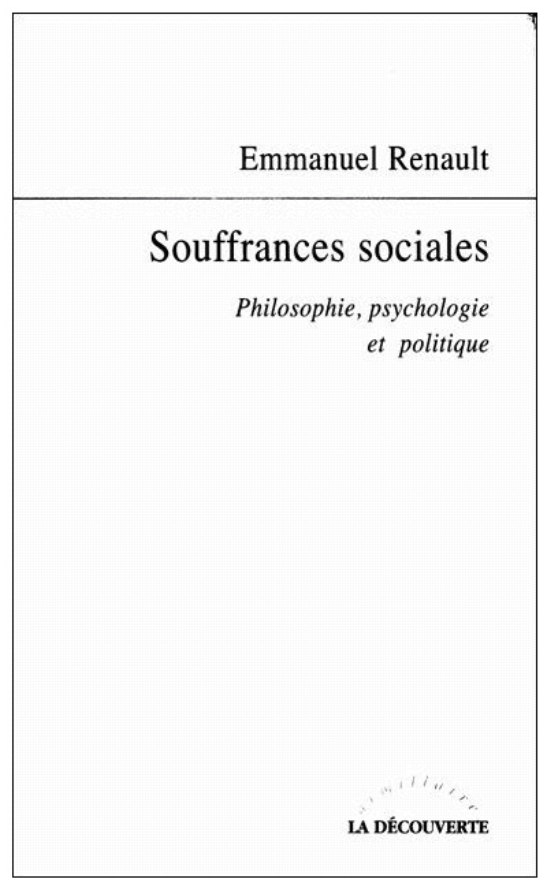

Paris: La Découverte, 2008

ISBN: 978-2707154019 
que analisou, no final do século XX, de modo detalhado, os distúrbios provocados pelo trabalho industrial sobre a saúde mental do trabalhador e que tem inaugurado um vasto programa de pesquisas em psicopatologia do trabalho, posteriormente adaptado em psicodinâmica do trabalho. Numa linha semelhante, podemos indicar os estudos de Michèle Salmona sobre o sofrimento social no mundo rural (contexto mais raro que o mundo industrial), em particular entre pequenos produtores de regiões agrícolas declinantes na França, onde a ocorrência de depressões e suicídios é muito alta.

Emmanuel Renault faz uma importante revisão da literatura internacional consagrada ao sofrimento social. Entre os livros marcantes para a elaboração do conceito de sofrimento, além a contribuição de Christophe Dejours, é destacado o estudo coletivo de Pierre Bourdieu, baseado em entrevistas dos novos pobres que surgiram das conseqüências da reestruturação industrial da época. Remontando no tempo, observa-se que F. Engels havia descrito, em 1845, a situação das classes laboriosas na Inglaterra em termos que mostravam a dureza da existência, e que S. Freud, em seu ensaio sobre o mal-estar na cultura ou na civilização, mostrou uma situação que se aproxima do sofrimento social.

No entanto, segundo E. Renault, o termo sofrimento social tem sido criticado ou mesmo evitado por autores da linha de Foucault que vêem no seu uso um risco de "psicologizar' ou até de "medicalizar" a realidade social. Por sua vez, autores marxistas teriam visto no sofrimento social um modo de dissimular "o peso das estruturas de dominação e de exploração” (p. 6).

$\mathrm{O}$ autor se refere também a importantes contribuições publicadas nos Estados Unidos sobre o mesmo tema, como as de A. Kleinmann, V. Das, M. Lock, N. Shaper-Hughes, I. Wilkinson. Também são levadas em consideração trabalhos de autores alemães, a começar pelos do filósofo Axel Honneth (A sociedade do desprezo), continuador da teoria crítica, e a obra clássica de H. P. Dreitzel sobre a patologia social.

Os artigos de Nancy Shaper-Hughes, em particular, chamarão a atenção do leitor brasileiro, já que a autora se refere especificamente ao sofrimento social no Brasil, ao descrever fatos como, condições de vida em favelas, miséria e fome no campo, violência policial, insatisfação de necessidades sociais de base, mortalidade infantil no Nordeste, às vezes consentida em certas categorias da população. Tais situações já foram amplamente descritas no Brasil, mas raramente como ilustração do conceito de sofrimento social nas ciências sociais. No âmbito do debate político, o termo parece ser ainda bastante desconhecido.

O livro de E. Renault é estruturado em seis capítulos. No capítulo 1, intitulado "Obstáculos e problemas", o autor apresenta como o conceito de sofrimento social está se firmando no cenário das ciências sociais e da filosofia, apesar das objeções de diversas correntes de pensamento. No capítulo 2, "Um vocabulário político", o autor mostra como o termo em questão tem sido progressivamente utilizado nos discursos políticos no passado, especialmente como argumento de denúncia das injustiças sociais ou de crítica ao sistema capitalista. Nesse sentido, são apontando "os constrangimentos de trabalho sobre a subjetividade, a questão do modo de interiorização e do vivido desses constrangimentos [...] como indica a emergência, enquanto preocupação pública, do estresse, do assédio, o caráter penoso das condições de trabalho e dos suicídios que induz. O vocabulário do sofrimento permite também revelar o aspecto insuportável da experiência da precariedade e da exclusão" (p. 138). No capítulo 3, "A atual controvérsia" o autor mostra como o sofrimento, como vocábulo político, se insere no discurso sobre as políticas neoliberais, vistas como causadoras de precariedade e de exclusão social. Também o termo se institucionaliza e se torna palavrachave de políticas públicas destinadas às populações carentes. No contexto francês, Dejours e Bourdieu tiveram voz ativa nesse debate. No capítulo 4, "Quatro modelos de patologia social", o autor dialoga com grandes expoentes da sociologia clássica (Durkheim), da medicina social (L.R. Villermé, J.R. Guérin, G. Rosen) e da psicologia social vinculada à psicanálise (S. Freud) para problematizar a patologia social, da qual o sofrimento, sob diversas formas, seria expressão. Com base na revisão dessa extensa literatura, o autor constrói sua própria visão no capítulo 5, "Os contornos de uma conceitualização". O conceito de sofrimento adquire maior complexidade pela articulação dos aspectos físico e psicológico. O sofrimento psicológico se subdivide em sofrimento psíquico e sofrimento psicossocial. Este último, por sua vez, se subdivide em sofrimento ético e sofrimento moral ( $p$. 310). Adquirindo maior dimensão, o sofrimento social é concebido de um ponto de vista dinâmico e é explicado por diferentes fatores sociais de sofrimentos, relacionados com as condições de vida e de trabalho. No capítulo 6, "Sofrimento e crítica social", o tema é retomado como argumento de discurso teórico-crítico sobre os efeitos da sociedade, sobre as questões de justiça, de realização de si, de alienação ou de desprezo que, em contexto recente, é geralmente associado ao predomínio do neoliberalismo, a partir das décadas de 1980 e 1990.

Em suma, o livro de Emmanuel Renault é excelente como introdução aos estudos sobre conceito de sofrimento social, com bases filosóficas, psicológicas e políticas. Apresenta o estado da arte levando em conta os estudos diferenciados que abrangem questões relacionadas à psicologia do trabalho (efeitos nocivos do trabalho industrial sobre a mente e o corpo do trabalhador) e à sociologia moral de política (conceituação da injustiça denunciada pela evocação do sofrimento social). O uso crítico do sofrimento social é fonte de argumentos para o discurso político, apontando as conseqüências negativas de certas políticas econômicas e sociais sobre as condições de vida e de trabalho de certas populações, assim como os riscos a que se expõe a vida dos indivíduos, em particular no plano psíquico. Mostrar o sofrimento em uma sociedade que dispõe de poderosos meios de comunicação de massa, que costumam dissimulá-lo pode constituir o eixo de uma ação política e intelectual. Por fim, trata-se de um livro eminentemente teórico e conceitual, pois não se 
refere a estudos de caso, mas várias situações concretas são mencionadas, inclusive as do Brasil.

\section{Fontes de consulta}

Benasayag M, Schmit G. Les passions tristes. Souffrance psychologique et crise sociale. Paris: La Découverte; 2003.

Boltanski L. La souffrance à distance. Partis: Métailié; 1993.

Bourdieu P. La misère du monde. Paris, Seuil; 1993. [Tradução brasileira: A miséria do mundo. Petrópolis: Vozes; 2003].

Dejours C. La souffrance en France. La banalisation de l'injustice sociale. Paris: Seuil; 1998. [Tradução brasileira: Banalização da injustiça social. Rio de Janeiro: FGV; 2007].

Dejours C. Travail, usure mentale. Paris: Bayard; 2000. [Tradução brasileira: A loucura do trabalho. São Paulo: Cortez; 2003].

Dejours C. Conjurer la violence. Travail, violence, santé. Paris: Payot; 2007.

Dreitzel HP. Die Gesellschftlichen Leiden und das Leiden an der Gesellschaft. Vorstudien zu einer Pathologie des Rollenvershaltens. Stuttgart: Ferdinand Enke Verlag; 1972.

Engels F. La situation de la classe laborieuse em Angleterre. Paris: Éditions sociales; 1975. [Tradução brasileira: A situação da classe laboriosa na Inglaterra. São Paulo: Boitempo Editorial; 2008].

Fassin D. Des maux indicibles. Sociologie des lieux d'écoute. Paris: La Découverte; 2004.
Freud S. Le malaise dans la culture. Paris: PUF; 1995. [Tradução brasileira: O futuro de uma ilusão; O mal-estar na civilização. Rio de Janeiro: Imago; 2006].

Furtos J, Laval C. La santé mentale en actes. De la clinique au politique. Toulouse: Érès; 2005.

Honneth A. La société du mépris. Vers une nouvelle théorie critique. Paris: La Découverte; 2006.

Ion J. Travail social et souffrance psychique. Paris: Dunod; 2005.

Joubert M, Louzon C. Répondre à la souffrance sociale. Toulouse: Érès; 2005.

Kleinmann A, Das V, Lock M. Social suffering. Los Angeles: University of California Press, Berkeley; 1997.

Renault E. L'expérience de l'injustice. Paris. La Découverte; 2004.

Salmona M. Souffrances et résistances des paysans Français. Paris: L'Harmattan; 1994.

Shaper-Hughes N. Mourir en silence. La violence ordinaire d'une ville brésilienne. Actes de la recherche en sciences sociales 1994: 104.

Shaper-Hughes N. Small wars and invisible genocides. Soc Sci Med 1996; 43(3): 888-90.

Vergely B. La souffrance. Recherche d'un sens perdu. Paris: Gallimard; 1997. [Tradução brasileira: O sofrimento. São Paulo: Edusc; 2000].

Wilkinson I. Suffering. A Sociological Introduction. Cambridge: Polity Press; 2005. 